\title{
Heart failure documentation
}

\section{in outpatients with diabetes and volume overload: an observational cohort study from the Diabetes Collaborative Registry}

\author{
Suzanne V. Arnold ${ }^{1 *} \mathbb{0}$, Philip G. Jones ${ }^{1}$, Michael Beasley², Jeanine Cordova ${ }^{3}$, Abhinav Goyall ${ }^{4}$, \\ Gregg C. Fonarow ${ }^{5}$ and Leo Seman ${ }^{3}$
}

\begin{abstract}
Background: Heart failure is a common and devastating complication of type 2 diabetes (T2D). Prompt recognition of heart failure may avert hospitalization, facilitate use of guideline-directed therapies, and impact choice of T2D medications. We sought to determine the rate and factors associated with heart failure documentation in T2D patients with evidence of volume overload requiring loop diuretics.

Methods: DCR is an on-going, prospective US registry of outpatient T2D patients from $>5000$ cardiology, endocrinology, and primary care clinicians (current analysis used data from 2013-2019). Among T2D patients receiving loop diuretics, we examined the rate of chart documentation of heart failure. We used a 3-level hierarchical logistic regression model (patients nested within physician within practice) to examine factors associated with heart failure diagnosis.

Results: Among 1,322,640 adults with T2D, 225,125 (17.0\%) were receiving a loop diuretic, of whom 91,969 (40.9\%) had documentation of heart failure. Male sex, lower body mass index, atrial fibrillation, chronic kidney disease, and coronary artery disease were associated with greater odds of heart failure diagnosis. After accounting for patient factors, patients seen by cardiologists were the most likely to have HF documented followed by PCPs and then endocrinologists.
\end{abstract}

Conclusions: Among US outpatients with T2D, 17\% of patients had evidence of volume overload — defined by loop diuretic prescription - of whom fewer than half had a clinical diagnosis of heart failure. While there may be non-heart failure indications for loop diuretics, our data suggest that a substantial proportion of T2D patients may have unrecognized heart failure and therefore could be missing opportunities for targeted therapies that could alter the clinical course of heart failure.

Keywords: Heart failure, Diabetes, Quality of care

*Correspondence: sarnold@saint-lukes.org

${ }^{1}$ Saint Luke's Mid America Heart Institute and University of MissouriKansas City, 4401 Wornall Rd, Kansas City, MO 64111, USA

Full list of author information is available at the end of the article

\section{Background}

While heart failure (HF) and type 2 diabetes (T2D) are individually highly prevalent and morbid, the intersection of the two is becoming increasingly recognized as a major health concern. HF in patients with T2D is predominantly due to diastolic dysfunction [1], and may or may not be associated with concomitant coronary artery

(c) The Author(s) 2020. This article is licensed under a Creative Commons Attribution 4.0 International License, which permits use, sharing, adaptation, distribution and reproduction in any medium or format, as long as you give appropriate credit to the original author(s) and the source, provide a link to the Creative Commons licence, and indicate if changes were made. The images or other third party material in this article are included in the article's Creative Commons licence, unless indicated otherwise in a credit line to the material. If material is not included in the article's Creative Commons licence and your intended use is not permitted by statutory regulation or exceeds the permitted use, you will need to obtain permission directly from the copyright holder. To view a copy of this licence, visit http://creativeco mmons.org/licenses/by/4.0/. The Creative Commons Public Domain Dedication waiver (http://creativecommons.org/publicdomain/ zero/1.0/) applies to the data made available in this article, unless otherwise stated in a credit line to the data. 
disease [2, 3]. Establishing a diagnosis of HF in patients with T2D is not only important from a prognosis perspective but could have important treatment implications. Use of guideline-directed medical therapy for HF (especially in the setting of left ventricular dysfunction) can substantially reduce the risk of hospitalization and mortality [4]. In addition, the presence or absence of HF has important implications in the management of T2D. For example, metformin $[5,6]$ and sodium-glucose cotransporter-2 (SGLT-2) inhibitors [7, 8] may be beneficial in patients with HF whereas thiazolidinediones $[9,10]$ and, possibly, some dipeptidyl peptidase- 4 inhibitors [11, 12] should be avoided (or used with caution). As HF is often slowly progressive and symptoms such as dyspnea could be attributed to other conditions, recognizing HF in the ambulatory setting may be challenging, but early recognition could allow for appropriate medical therapy to be initiated prior to overt HF requiring hospitalization. In order to better define the potential gap in care from a lack of identification of co-morbid HF in outpatients with T2D, we used the Diabetes Collaborative Registry (DCR) to determine the rate and factors associated with HF diagnosis in T2D patients with evidence of volume overload requiring loop diuretics.

\section{Methods}

\section{Patient population}

DCR is a US-based, outpatient, quality improvement registry that began in 2014 (with data collected retrospectively from 2013 and available through Q1 2019 for this analysis) as a collaborative effort by endocrinology, primary care, and cardiology professional societies [13]. DCR was designed to understand the care of patients with diabetes across the spectrum of primary and specialty care and currently includes 379 practices (174 primary care, 182 cardiology, 23 endocrinology) and 5133 providers. Data are collected through an automated system integration solution that extracts relevant data elements from electronic health records (including patient demographics, comorbidities, and medications). This study was limited to adults with T2D, and the most recent clinic visit was used for analysis.

The primary outcome for this study was chart documentation of HF in patients with evidence of volume overload requiring prescription of loop diuretics. We acknowledge that use of loop diuretics is a moderate surrogate for diagnosis of HF, as (1) patients could have indolent HF that is not recognized and therefore not on loop diuretics and (2) patients may be on loop diuretics for another indication (e.g., hypertension with advanced chronic kidney disease). In a real-world registry without routine measurements of left ventricular pressures, however, we believe that the use of loop diuretics is the best surrogate available for volume overload, which in the majority of patients is indicative of some degree of HF. We excluded patients with chronic liver disease, as these patients could have volume overload without HF. Because participation in the registry requires no data collection beyond that of the routine clinical care and all collected data are de-identified, a waiver of written informed consent and authorization for this study was granted by Chesapeake Research Review Incorporated.

\section{Statistical analysis}

Among patients on loop diuretics, demographic and clinical characteristics were compared between patients who did versus did not have a chart diagnosis of HF using standardized differences $(>10 \%$ difference is considered clinically relevant [14]). A 3-level hierarchical logistic regression model was used to examine the association of patient factors and provider specialty with documentation of HF. Patient factors included age, sex, race, body mass index, coronary artery disease, chronic kidney disease, and atrial fibrillation. Splines were included for continuous variables to explore non-linear associations. Provider and practice were both included as random effects to account for the clustering of patients within providers and also clustering of providers within practices. Total variability across providers was quantified by the median odds ratio (combining both the provider- and practice-level effects), which estimates the average relative difference in odds of documentation of HF between 2 different providers for patients with identical covariates. Missing covariate data were imputed using multiple imputation methods. The imputation model included all variables in the analytic model. Imputed values were obtained using random forests, as implemented in the $\mathrm{R}$ package 'missRanger' [15]. Twenty randomly imputed data sets were obtained, the above model was fit on all data sets, and model estimates were pooled using Rubin's method to obtain final estimates of odds ratios and confidence intervals [16]. All analyses were performed with SAS version 9.4 (SAS Institute, Cary, North Carolina) and R version 3.6.3 (R Core Team, Vienna, Austria). All $\mathrm{p}$-values are 2 -sided tests and were considered statistically significant at $<0.05$.

\section{Results \\ Study cohort}

There were 1,482,642 adults with T2D enrolled in DCR from 2013-2019, of whom 160,002 patients had chronic liver disease and were excluded from the analysis. Among the $1,322,640$ remaining patients, 225,125 patients (17.0\%) were prescribed a loop diuretic and formed the primary analytic cohort. Mean age was $70.6 \pm 11.9$ years, 
Table 1 Patient characteristics according to documentation of heart failure

\begin{tabular}{|c|c|c|c|c|}
\hline & $\begin{array}{l}\text { All Patients on loop diuretics } \\
n=215,957\end{array}$ & $\begin{array}{l}\text { Heart failure documented } \\
n=110,809\end{array}$ & $\begin{array}{l}\text { Heart failure not documented } \\
n=105,148\end{array}$ & $\begin{array}{l}\text { Standardized } \\
\text { difference }^{\mathrm{a}}\end{array}$ \\
\hline Age (years) & $70.6 \pm 11.9$ & $72.1 \pm 11.8$ & $69.5 \pm 11.9$ & $22.7 \%$ \\
\hline Men & $106,584 / 225,111(47.3 \%)$ & 48,867/91,965 (53.1\%) & $57,717 / 133,146(43.3 \%)$ & $19.7 \%$ \\
\hline Race & & & & $4.4 \%$ \\
\hline White & $135,394 / 161,754$ (83.7\%) & $54,130 / 65,360$ (82.8\%) & $81,264 / 96,394$ (84.3\%) & \\
\hline Black & $23,239 / 161,754$ (14.4\%) & $9804 / 65,360$ (15.0\%) & 13,435/96,394 (13.9\%) & \\
\hline Other & $3001 / 161,754(1.9 \%)$ & $1370 / 65,360(2.1 \%)$ & $1631 / 96,394$ (1.7\%) & \\
\hline Multiracial & $120 / 161,754(0.1 \%)$ & $56 / 65,360(0.1 \%)$ & $64 / 96,394(0.1 \%)$ & \\
\hline Body mass index $\left(\mathrm{kg} / \mathrm{m}^{2}\right)$ & $34.4 \pm 8.7(n=161,705)$ & $33.3 \pm 8.5(n=67,707)$ & $35.2 \pm 8.7(n=93,998)$ & $21.8 \%$ \\
\hline Current smoker & $67,481 / 215,433$ (31.3\%) & 28,506/88,703 (32.1\%) & $38,975 / 126,730$ (30.8\%) & $10.2 \%$ \\
\hline Hypertension & $198,558(88.2 \%)$ & $83,614(90.9 \%)$ & $114,944(86.3 \%)$ & $14.5 \%$ \\
\hline Dyslipidemia & $170,251(75.6 \%)$ & $72,169(78.5 \%)$ & $98,082(73.7 \%)$ & $11.3 \%$ \\
\hline Coronary artery disease & $124,602(55.3 \%)$ & $64,937(70.6 \%)$ & $59,665(44.8 \%)$ & $54.1 \%$ \\
\hline Prior myocardial infarction & 26,765 (11.9\%) & $16,727(18.2 \%)$ & $10,038(7.5 \%)$ & $32.2 \%$ \\
\hline Prior stroke & $48,692(21.6 \%)$ & $23,257(25.3 \%)$ & 25,435 (19.1\%) & $14.9 \%$ \\
\hline Atrial fibrillation/flutter & $70,661(31.4 \%)$ & $41,917(45.6 \%)$ & $28,744(21.6 \%)$ & $52.5 \%$ \\
\hline Chronic kidney disease & $10,131(4.5 \%)$ & $4429(4.8 \%)$ & $5702(4.3 \%)$ & $2.6 \%$ \\
\hline Systolic blood pressure (mmHg) & $129.0 \pm 18.4(n=211,968)$ & $126.7 \pm 18.7(n=87,160)$ & $130.6 \pm 18.0(n=124,808)$ & $21.2 \%$ \\
\hline Diastolic blood pressure (mmHg) & $72.6 \pm 10.8(n=211,781)$ & $71.4 \pm 11.0(n=87,079)$ & $73.5 \pm 10.7(n=124,702)$ & $19.8 \%$ \\
\hline LV function documented & $97,728(43.4 \%)$ & $54,560(59.3 \%)$ & $43,168(32.4 \%)$ & $56.1 \%$ \\
\hline LV function & & & & $67.6 \%$ \\
\hline Hyperdynamic (> 70\%) & $5464 / 97,728(5.6 \%)$ & $2015 / 54,560(3.7 \%)$ & $3449 / 43,168$ (8.0\%) & \\
\hline Normal (50-70\%) & $60,698 / 97,728$ (62.1\%) & $28,108 / 54,560$ (51.5\%) & $32,590 / 43,168$ (75.5\%) & \\
\hline Mildly reduced (40-49\%) & $12,636 / 97,728(12.9 \%)$ & $8785 / 54,560(16.1 \%)$ & $3851 / 43,168(8.9 \%)$ & \\
\hline Moderately reduced (30-39\%) & $9606 / 97,728(9.8 \%)$ & $7762 / 54,560(14.2 \%)$ & $1844 / 43,168(4.3 \%)$ & \\
\hline Severely reduced $(<30 \%)$ & $9324 / 97,728(9.5 \%)$ & $7890 / 54,560(14.5 \%)$ & $1434 / 43,168(3.3 \%)$ & \\
\hline Beta blocker & $174,779(77.6 \%)$ & $80,424(87.4 \%)$ & $94,355(70.9 \%)$ & $41.7 \%$ \\
\hline ACE inhibitor or ARB & $166,536(74.0 \%)$ & $68,787(74.8 \%)$ & $97,749(73.4 \%)$ & $3.2 \%$ \\
\hline \multicolumn{5}{|l|}{ Diabetes medications } \\
\hline Insulin & $81,480(36.2 \%)$ & $33,705(36.6 \%)$ & $47,775(35.9 \%)$ & $1.6 \%$ \\
\hline Metformin & $108,987(48.4 \%)$ & $41,894(45.6 \%)$ & $67,093(50.4 \%)$ & $9.7 \%$ \\
\hline Sulfonylurea & $66,620(29.6 \%)$ & $28,085(30.5 \%)$ & 38,535 (28.9\%) & $3.5 \%$ \\
\hline Thiazolidinedione & $14,920(6.6 \%)$ & $4732(5.1 \%)$ & $10,188(7.7 \%)$ & $10.3 \%$ \\
\hline DPP-4 inhibitor & 34,038 (15.1\%) & 13,149 (14.3\%) & $20,889(15.7 \%)$ & $3.9 \%$ \\
\hline GLP-1 agonist & $19,384(8.6 \%)$ & 5705 (6.2\%) & $13,679(10.3 \%)$ & $14.8 \%$ \\
\hline SGLT-2 inhibitor & $13,462(6.0 \%)$ & 4015 (4.4\%) & $9447(7.1 \%)$ & $11.8 \%$ \\
\hline
\end{tabular}

Data are presented as mean \pm standard deviation, $\mathrm{n}(\%)$, or $\mathrm{n} / \mathrm{N}(\%)$ if reported data are lower than column header $L V$ left ventricular, $A C E$ angiotensin converting enzyme, $A R B$ angiotensin II receptor blocker, DPP dipeptidyl peptidase, GLP glucagon-like peptide, SGLT sodiumglucose cotransporter

a $>10 \%$ is considered a clinical relevant difference [14]

$0.752 \%$ were women, $55.3 \%$ had coronary artery disease, and $4.5 \%$ had chronic kidney disease (Table 1).

\section{HF documentation}

Among 225,125 patients who were prescribed loop diuretics, HF was documented in 91,969 patients (40.9\%), and the demographics, comorbidities, and glucose-lowering medications of patients who did versus did not have
HF documented are shown in Table 1. Patients with HF documented were more likely to have left ventricular function documented (HF documented vs. no: $59.3 \%$ vs. $32.4 \%$, standardized difference $56.1 \%$ ) and to be on beta blockers ( $87.4 \%$ vs. $70.9 \%$, standardized difference $41.7 \%)$ but had similar use of ACE inhibitors/ARBs (74.8\% vs. 73.4\%, standardized difference 3.2\%). Patients with HF documented were less likely to be treated with metformin 
(HF documented vs. no: $45.6 \%$ vs. $50.4 \%$, standardized difference $9.7 \%$ ), thiazolidinediones $(5.1 \%$ vs. $7.7 \%$, standardized difference 10.3\%), GLP-1 receptor agonists (6.2\% vs. $10.3 \%$, standardized difference $14.8 \%$ ), and SGLT2 inhibitors (4.4\$ vs. $7.1 \%$, standardized difference $11.8 \%$ ).

In the hierarchical logistic regression model, female sex and higher body mass index were independently associated with a lower odds of HF documentation (Fig. 1). Black race, coronary artery disease, chronic kidney disease, and atrial fibrillation were each associated with a greater odds of HF documentation. After accounting for patient factors, patients seen by cardiologists were the most likely to have HF documented followed by primary care physicians and then endocrinologists (Additional file 1: Table S1). There was also substantial variation across providers in whether or not HF was documented, with probabilities of documentation ranging from near $0 \%$ to near $100 \%$ (Fig. 2). The median odds ratio was 2.50 , indicating that, for two randomly selected providers of the same specialty seeing patients with identical covariates, there is $50 \%$ chance of a greater than 2.5 -fold difference in the odds of HF documentation between the two providers.

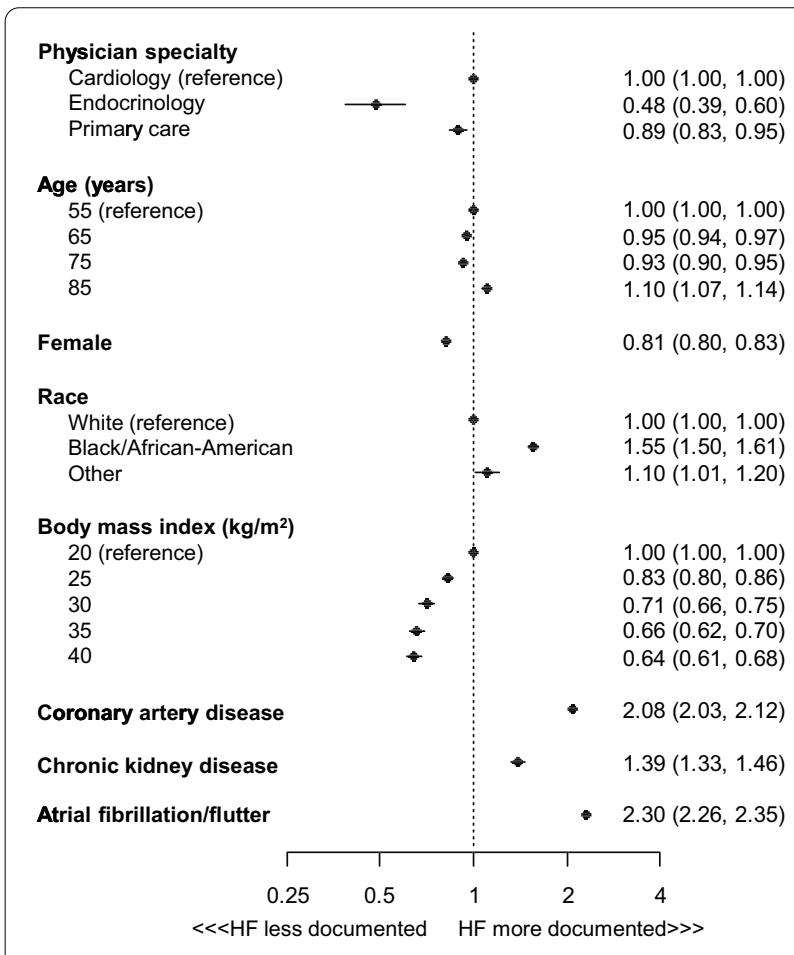

Adjusted Odds of HF Documentation $(95 \% \mathrm{Cl})$

Fig. 1 Association of patient factors and specialty on documentation of heart failure in T2D patients on loop diuretics

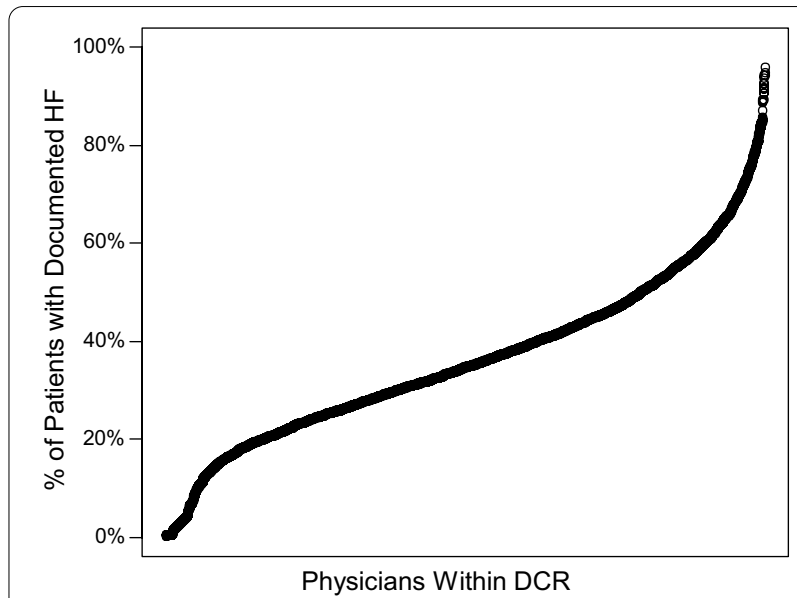

Fig. 2 Physician-level variability in documentation of heart failure. Each circle represents an individual physician in DCR and the percentage of patients that physician saw who were on loop diuretics and had heart failure documented. The $x$-axis indicates physicians in DCR ordered by percentage of patients with heart failure documented

\section{Discussion}

In a large US database of adults with T2D from cardiology, endocrinology, and primary care outpatient practices, $17 \%$ had evidence of volume overload requiring prescription of loop diuretics, of whom over half did not have HF documented. Patients who were female, obese, and who did not have cardiovascular diseases were less likely to have HF documented. Furthermore, even after accounting for differences in patient characteristics, there was substantial variation across providers in the documentation of HF, suggesting that some providers are more diligent at recognizing and documenting HF in patients with evidence of volume overload. Documentation appeared to impact cardiac testing (evaluation of left ventricular function), use of beta blockers, and choice of glucose-lowering medications, with lower use metformin and SGLT2 inhibitors (paradoxically, given their benefit in patients with HF [5, 17-19], prescription patterns that have been previously noted [1]) and thiazolidinediones in patients in whom HF was documented. These data suggest that a substantial proportion of T2D patients may have unrecognized HF and could be missing opportunities for targeted therapies that could impact outcomes [4, $5,7]$.

\section{Implications}

HF is a particularly morbid condition, increasing the risk of hospitalization [20-22], increasing healthcare costs [23], and worsening patients' quality of life [24]. Volume overload that leads to hospitalization typically prompts laboratory and imaging tests that permit 
a straightforward diagnosis of HF. However, the subtler signs and symptoms of indolent HF may be overlooked in the ambulatory setting, with the dyspnea and exercise intolerance attributed to obesity, deconditioning, or age. Furthermore, as HF in patients with T2D is more likely to occur with preserved ejection fraction [1] and often occurs in the absence of coronary disease [3], common triggers for a HF diagnosis are often absent. Nonetheless, prompt recognition of HF in the ambulatory office could influence choice of glucose-lowering medications and potentially trigger cardiology referral, laboratory or imaging tests, and closer monitoring of volume status-all of which could help avert HF hospitalization and improve outcomes $[25,26]$. Furthermore, if the prompted imaging tests demonstrate reduced left ventricular ejection fraction, a number of evidence-based treatments could be instituted to improve outcomes (e.g., angiotensin converting enzyme-inhibitors, beta blockers, defibrillators). Greater recognition of the high prevalence of HF as well as the differences in presentation of HF in patients with T2D (more HF with preserved ejection fraction, less associated with coronary disease) may help providers more consistently diagnose HF in patients with T2D and evidence of volume overload.

\section{Limitations}

First and most importantly, we used prescription of loop diuretics as a surrogate marker for HF, but this may under- or over-estimate the proportion of patients with clinical HF. As mentioned above, dyspnea with more subtle volume overload due to HF may be falsely attributed to obesity, deconditioning, lung disease, or age, and therefore may not treated with diuretics. Furthermore, patients could have HF that is managed through salt and fluid restriction and not require diuretics for management (e.g., $36 \%$ of patients in DCR with left ventricular dysfunction were not on loop diuretics [27]). Conversely, patients may not have HF and still be treated with loop diuretics [appropriately or inappropriately (e.g., venous insufficiency)]. There are a few indications for loop diuretics other than volume overload (hypertension with advanced chronic kidney disease, nephrotic syndrome, cirrhosis), although these impact a fairly limited proportion of patients. As such, without comprehensive testing of left ventricular pressures, we cannot be certain of the true prevalence of HF in ambulatory patients with T2D. Second, it is possible that HF was recognized by the provider but not documented in the electronic health record. This is particularly an issue with endocrinologists who may be uncomfortable assigning a diagnosis of HF, which is considered outside of their specialty. Third, other than some evidence of an impact on choice of glucoselowering medications, we cannot determine if there is any clinical consequence of a lack of HF documentation in patients on loop diuretics. Further longitudinal work is needed to define the association of a lack of HF documentation with incident HF hospitalization or other outcomes (e.g., costs, mortality).

\section{Conclusion}

In a large US cohort of outpatients with T2D, 17\% of patients had evidence of volume overload requiring prescription of loop diuretics, fewer than half of whom had documentation of HF. While there may be non-HF indications for loop diuretics, our data suggest that a substantial proportion of patients with T2D have unrecognized HF and may be missing targeted interventions that could potentially alter the clinical course of HF and reduce the risk of hospitalization and mortality.

\section{Supplementary Information}

The online version contains supplementary material available at https://doi. org/10.1186/s12933-020-01190-6.

Additional file 1: Table S1. Patient characteristics according to documentation of heart failure, stratified by physician specialty.

\section{Abbreviations}

HF: Heart failure; T2D: Type 2 diabetes; SGLT2: Sodium-glucose co-transporter-2; DCR: Diabetes Collaborative Registry.

\section{Acknowledgements}

Not applicable.

\section{Authors' contributions}

SVA: conceptualization, data curation, formal analysis, investigation, methodology, original draft; PGJ: conceptualization, formal analysis, investigation, methodology, review and editing; MB: investigation, methodology, review and editing; JC: conceptualization, investigation, methodology, review and editing; AG: investigation, methodology, review and editing; GCF: investigation, methodology, review and editing; LS: conceptualization, investigation, methodology, review and editing. All authors read and approved the final manuscript.

\section{Funding \\ The Diabetes Collaborative Registry is funded by AstraZeneca (founding spon- sor) and Boehringer Ingelheim. The co-authors from Boehringer Ingelheim reviewed and edited the manuscript for intellectual content; however, the sponsors of the registry had no role in the final review and approval of the manuscript for submission.}

\section{Availability of data and materials}

The data that support the findings of this study are available from the Diabetes Collaborative Registry, but restrictions apply to the availability of these data, which were used under specified agreement for the current study, and so are not publicly available. Data are however available from the authors upon reasonable request and with permission of DCR.

\section{Ethics approval and consent to participate}

A waiver of written informed consent and authorization for this study was granted by Chesapeake Research Review Incorporated. 


\section{Consent for publication}

SVA and PGJ had full access to the study data and take complete responsibility for the integrity of the data and the accuracy of the data analysis. All authors approved the manuscript for publication.

\section{Competing interests}

JC and LS: Employees of Boehringer Ingelheim Pharmaceuticals. GCF: Consulting for Abbott, Amgen, AstraZeneca, Bayer, Janssen, Novartis, and Medtronic. The remaining authors report no relevant disclosures to the current manuscript.

\section{Author details}

1 Saint Luke's Mid America Heart Institute and University of Missouri-Kansas City, 4401 Wornall Rd, Kansas City, MO 64111, USA. ${ }^{2}$ Yale University School of Medicine, New Haven, CT, USA. ${ }^{3}$ Boehringer Ingelheim Pharmaceuticals, Ridgefield, CT, USA. ${ }^{4}$ Emory University School of Medicine, Atlanta, GA, USA.

${ }^{5}$ University of California, Los Angeles, Los Angeles, CA, USA.

Received: 2 October 2020 Accepted: 2 December 2020

Published online: 12 December 2020

\section{References}

1. Arnold SV, Echouffo-Tcheugui JB, Lam CS, Inzucchi SE, Tang F, McGuire DK, Goyal A, Maddox TM, Sperling LS, Fonarow GC, et al. Patterns of glucose-lowering medication use in patients with type 2 diabetes and heart failure. Insights from the Diabetes Collaborative Registry (DCR). Am Heart J. 2018:203:25-9.

2. Nichols GA, Koro CE, Gullion CM, Ephross SA, Brown JB. The incidence of congestive heart failure associated with antidiabetic therapies. Diabetes Metab Res Rev. 2005;21(1):51-7.

3. Cavender MA, Steg PG, Smith SC Jr, Eagle K, Ohman EM, Goto S, Kuder J, Im K, Wilson PW, Bhatt DL, et al. Impact of diabetes mellitus on hospitalization for heart failure, cardiovascular events, and death: outcomes at 4 years from the reduction of atherothrombosis for Continued health (REACH) registry. Circulation. 2015;132(10):923-31.

4. Yancy CW, Jessup M, Bozkurt B, Butler J, Casey DE Jr, Colvin MM, Drazner MH, Filippatos GS, Fonarow GC, Givertz MM, et al. 2017 ACC/AHA/HFSA focused update of the 2013 ACCF/AHA guideline for the management of heart failure: a report of the American College of Cardiology/American Heart Association Task Force on Clinical Practice Guidelines and the Heart Failure Society of America. Circulation. 2017;136(6):e137-61.

5. Masoudi FA, Inzucchi SE, Wang Y, Havranek EP, Foody JM, Krumholz HM. Thiazolidinediones, metformin, and outcomes in older patients with diabetes and heart failure: an observational study. Circulation. 2005;111(5):583-90.

6. Eurich DT, Weir DL, Majumdar SR, Tsuyuki RT, Johnson JA, Tjosvold L, Vanderloo SE, McAlister FA. Comparative safety and effectiveness of metformin in patients with diabetes mellitus and heart failure: systematic review of observational studies involving 34,000 patients. Circ Heart Fail. 2013;6(3):395-402.

7. Zinman B, Wanner C, Lachin JM, Fitchett D, Bluhmki E, Hantel S, Mattheus M, Devins T, Johansen OE, Woerle HJ, et al. Empagliflozin, cardiovascular outcomes, and mortality in type 2 diabetes. N Engl J Med. 2015;373(22):2117-28.

8. Radholm K, Figtree G, Perkovic V, Solomon SD, Mahaffey KW, de Zeeuw D, Fulcher G, Barrett TD, Shaw W, Desai M, et al. Canagliflozin and heart failure in type 2 diabetes mellitus: results from the CANVAS program (Canagliflozin Cardiovascular Assessment Study). Circulation. 2018;138:458-68.

9. Lago RM, Singh PP, Nesto RW. Congestive heart failure and cardiovascular death in patients with prediabetes and type 2 diabetes given thiazolidinediones: a meta-analysis of randomised clinical trials. Lancet. 2007:370(9593):1129-36.

10. Nissen SE, Wolski K. Effect of rosiglitazone on the risk of myocardial infarction and death from cardiovascular causes. N Engl J Med. 2007;356(24):2457-71.

11. Scirica BM, Bhatt DL, Braunwald E, Steg PG, Davidson J, Hirshberg B, Ohman P, Frederich R, Wiviott SD, Hoffman EB, et al. Saxagliptin and cardiovascular outcomes in patients with type 2 diabetes mellitus. N Engl Med. 2013;369(14):1317-26.

12. White WB, Cannon CP, Heller SR, Nissen SE, Bergenstal RM, Bakris GL, Perez AT, Fleck PR, Mehta CR, Kupfer S, et al. Alogliptin after acute coronary syndrome in patients with type 2 diabetes. N Engl J Med. 2013;369(14):1327-35.

13. Arnold SV, Inzucchi SE, McGuire DK, Mehta SN, Goyal A, Sperling LS, Maddox TM, Einhorn D, Wong ND, Ratner RE, et al. Evaluating the quality of comprehensive cardiometabolic care for patients with type 2 diabetes in the U.S.: the Diabetes Collaborative Registry. Diabetes Care. 2016;39(7):e99-101.

14. Austin PC. Balance diagnostics for comparing the distribution of baseline covariates between treatment groups in propensity-score matched samples. Stat Med. 2009;28(25):3083-107.

15. Mayer M. missRanger: fast imputation of missing values. $R$ package version 2.1.0; 2019. https://CRAN.R-project.org/package=missRanger.

16. Rubin DB. Multiple imputation for nonresponse in surveys. New York: John Wiley \& Sons; 1987.

17. Zelniker TA, Wiviott SD, Raz I, Im K, Goodrich EL, Bonaca MP, Mosenzon O, Kato ET, Cahn A, Furtado RHM, et al. SGLT2 inhibitors for primary and secondary prevention of cardiovascular and renal outcomes in type 2 diabetes: a systematic review and meta-analysis of cardiovascular outcome trials. Lancet. 2019;393(10166):31-9.

18. Packer M, Anker SD, Butler J, Filippatos G, Pocock SJ, Carson P, Januzzi J, Verma S, Tsutsui H, Brueckmann M, et al. Cardiovascular and renal outcomes with empagliflozin in heart failure. N Engl J Med. 2020;383(15):1413-24.

19. McMurray JJV, Solomon SD, Inzucchi SE, Kober L, Kosiborod MN, Martinez FA, Ponikowski P, Sabatine MS, Anand IS, Belohlavek J, et al. Dapagliflozin in patients with heart failure and reduced ejection fraction. N Engl J Med. 2019:381(21):1995-2008.

20. Michalsen A, Konig G, Thimme W. Preventable causative factors leading to hospital admission with decompensated heart failure. Heart (British Cardiac Society). 1998;80(5):437-41.

21. Tsuyuki RT, McKelvie RS, Arnold JM, Avezum A Jr, Barretto AC, Carvalho $A C$, Isaac DL, Kitching AD, Piegas LS, Teo KK, et al. Acute precipitants of congestive heart failure exacerbations. Arch Intern Med. 2001;161(19):2337-42.

22. Opasich C, Rapezzi C, Lucci D, Gorini M, Pozzar F, Zanelli E, Tavazzi L, Maggioni AP. Precipitating factors and decision-making processes of short-term worsening heart failure despite "optimal" treatment (from the IN-CHF Registry). Am J Cardiol. 2001:88(4):382-7.

23. Chan PS, Soto G, Jones PG, Nallamothu BK, Zhang Z, Weintraub WS, Spertus JA. Patient health status and costs in heart failure: insights from the eplerenone post-acute myocardial infarction heart failure efficacy and survival study (EPHESUS). Circulation. 2009:119(3):398-407.

24. Green CP, Porter CB, Bresnahan DR, Spertus JA. Development and evaluation of the Kansas City Cardiomyopathy Questionnaire: a new health status measure for heart failure. J Am Coll Cardiol. 2000;35(5):1245-55.

25. Ferreira JP, Metra M, Mordi I, Gregson J, Ter Maaten JM, Tromp J, Anker SD, Dickstein $\mathrm{K}$, Hillege $\mathrm{HL}$, Ng LL, et al. Heart failure in the outpatient versus inpatient setting: findings from the BIOSTAT-CHF study. Eur J Heart Fail. 2019:21(1):112-20.

26. Morieri ML, Longato E, Mazzucato M, Di Camillo B, Cocchiglia A, Gubian L, Sparacino G, Avogaro A, Fadini GP, Vigili de Kreutzenberg S. Improved long-term cardiovascular outcomes after intensive versus standard screening of diabetic complications: an observational study. Cardiovasc Diabetol. 2019;18(1):117.

27. Arnold SV, Yap J, Lam CSP, Tang F, Tay WT, Teng THK, McGuire DK, Januzzi $J L$, Fonarow GC, Masoudi FA, et al. Management of patients with diabetes and heart failure with reduced ejection fraction: An international comparison. Diabetes Obes Metab. 2019;21(2):261-6.

\section{Publisher's Note}

Springer Nature remains neutral with regard to jurisdictional claims in published maps and institutional affiliations. 